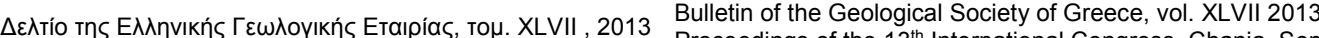
Proceedings of the $13^{\text {th }}$ International Congress, Chania Sept.

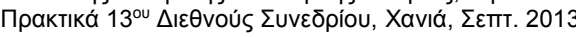
2013

\title{
GLOBALLY VALID RELATIONS CONVERTING MAGNITUDES OF INTERMEDIATE AND DEEP-FOCUS EARTHQUAKES TO Mw
}

\author{
Tsampas A.D. ${ }^{1}$, Scordilis E.M. ${ }^{1}$, Papazachos C.B. ${ }^{1}$ and \\ Karakaisis G.F. ${ }^{1}$ \\ ${ }^{1}$ Aristotle University of Thessaloniki, Faculty of Geology, Department of Geophysics, \\ atsampas@geo.auth.gr,manolis@geo.auth.gr,kpapaza@geo.auth.gr,karakais@geo.auth.gr
}

\begin{abstract}
An essential step in the compilation of homogeneous and complete earthquake cata$\log _{s}$ is the thorough investigation of potentially robust relations between different magnitude scales. The vast majority of already published relations usually concerns shallow-focus earthquake data with depths up to 60-70 km.

In the present study, several magnitude scales reported by 66 world-wide data providers in conjunction with published catalogs are examined within the depth range of 61-700 km, by applying least-squares regression analysis. Among other widely used scales, as body wave $\left(m_{b}, m_{B}\right)$ and surface wave $\left(M_{s}\right)$ magnitudes cited by International Centers (i.e. ISC, NEIC and IDC), the behavior of relevant magnitude scales determined by MOS (Moscow, Russia), BJI (Beijing, China), DJA (Djakarta, Indonesia) and the Japanese magnitude calculated by JMA, is also examined. By this way, robust calibrating relationships of 12 magnitude scales to the moment magnitudes provided by GCMT, NEIC and JMA are defined.

From the obtained results important observations on the behavior of certain magnitude scales were made. Thus, a remarkable variation of $m_{b}$ scale cited by IDC could be noted for intermediate and deep focus events. Furthermore, a comparison with the $M_{w}$ of NIED revealed an apparent lower "saturation" level around 5.0 below which the moment magnitude values published by GCMT and NEIC, are systematically overestimated.
\end{abstract}

Key words: Homogeneous intermediate and deep-focus earthquake catalog, moment magnitude, converting relations.

\section{Пєрі́ $\eta \psi \eta$}

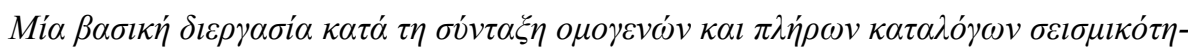

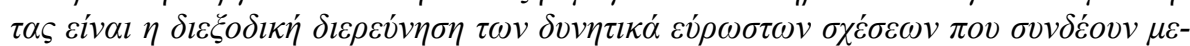

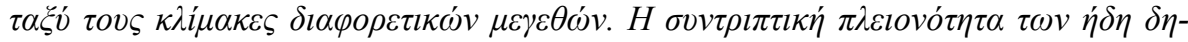

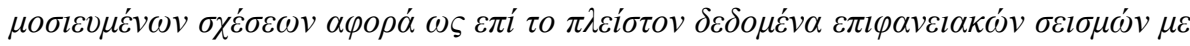

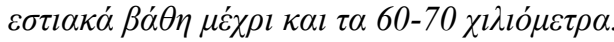

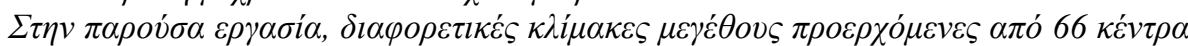

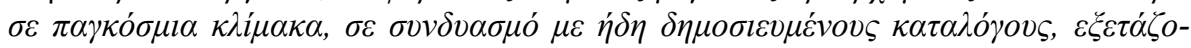

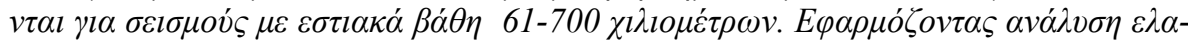

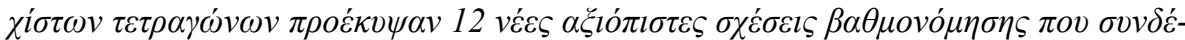

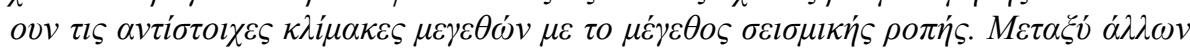

$\underline{\text { XLVII, No } 3-1316}$ 


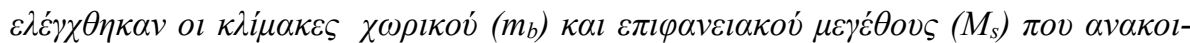

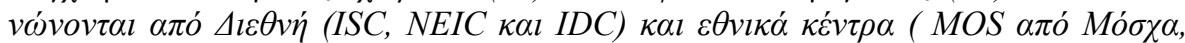

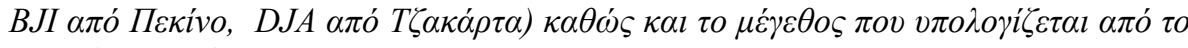
JMA (Ia $\pi \omega v i \alpha)$.

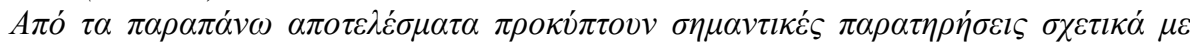

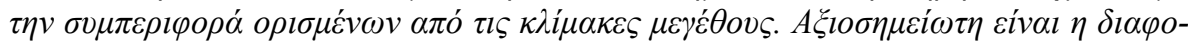

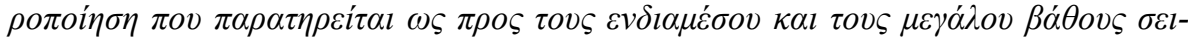

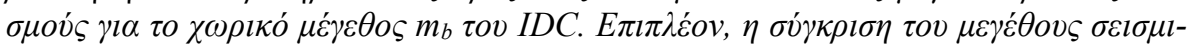

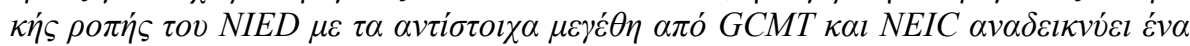

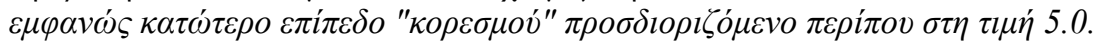

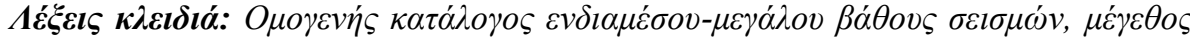

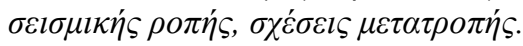

\section{Introduction}

Since Wadati presented his first results on the existence of a deep earthquake zone underneath Honshu (Wadati, 1928, 1929), research on intermediate-depth and deep-focus earthquakes has indicated the distinct nature of this particular type of seismic activity. It has been shown that intermediate-depth and deep-focus earthquakes can be clearly differentiated from the shallow ones since they occur only in certain geographical areas and follow different time and magnitude distributions (Dziewonski and Gilbert, 1974, Abe and Kanamori, 1979, Astiz et. al., 1988, Giardini, 1988, Okal and Kirby, 1995).

The size of earthquakes with focal depth $\mathrm{h} \geq 60 \mathrm{~km}$ remains a controversial issue since it is expressed in various magnitude scales. As it is known, body-wave magnitude is the conventional parameter for the quantification of the intermediate-depth and deep earthquakes. Recent relevant observations indicate a notable divergence in body wave magnitude $\left(\mathrm{m}_{\mathrm{b}}\right)$ estimations that were based on standard methodologies applied for shallow events of the same size. Abe and Kanamori (1979) used the broad-band body-wave magnitude (with average period of the body-waves between 4 and $15 \mathrm{sec}$ ) to quantify a number of deep-focus earthquakes that occurred during 19041974. Seismic moment of earthquakes, however, is the most appropriate parameter that represents their physical size.

In the present work, following similar studies of global shallow seismicity (Utsu, 2002, Scordilis, 2006), an attempt is made to define reliable converting relations which will be used for creating a homogeneous, in respect to magnitude, global catalog. Such catalog of intermediate-depth and deep-focus earthquakes could then be used for seismicity and seismic hazard studies.

\section{Data Compilation}

As basic data source in our study we used the on-line bulletins of ISC and NEIC to create an initial global catalog with earthquakes of focal depths, $\mathrm{h} \geq 60 \mathrm{~km}$ since 1964 . Earthquake parameters of events reported since 1964 were extracted and adopted as first-priority solutions in terms of origintime, epicenter coordinates and focal depths, constituting the main body of our data set. To augment the data, additional information on intermediate-depth and deep-focus earthquakes has been extracted from GCMT and JMA. After discarding erroneous entries (doublets or false events), additional magnitude information originated from reliable published earthquake catalogs (Rothe, 1969; Bath and Duda, 1979; Abe, 1981; Karnik, 1996; Engdahl \& Villaseñor, 2002) was also integrated in our dataset, thus enriching the earthquake catalog.

Moreover, reliable moment magnitude information published by GCMT, NEIC, JMA and the above mentioned earthquake catalogs, was adopted as well. Starting from 1962, according to first intermediate-deep entries mentioned by GCMT catalog, the extracted moment magnitudes were

$\underline{\text { XLVII, No } 3-1317}$ 
classified by merging equivalent moment scales into three discrete categories (Table1). The $\mathrm{M}_{\mathrm{w}} \mathrm{H}$ group includes moment magnitude information originated from: a) Global Centroid Moment Tensor (GCMT) catalog based on long period waveforms, b) the solutions given by the source parameter catalog (SOPAR) of NEIC, c) moment magnitude referred by Engdahl and Villaseñor's (2002) centennial catalog (CEC). Components of the second moment magnitude category, $\mathrm{M}_{\mathrm{w}} \mathrm{N}$, are: a) the NEIC moment magnitude, b) the so-called Preliminary Determinations of Epicenters (PDE) solutions provided by the source parameter catalog (SOPAR) of NEIC, c) the $\mathrm{M}_{\mathrm{w}} \mathrm{GS}$ of USGS referred in Engdahl and Villaseñor (2002). The third group includes only moment magnitudes calculated by the National Research Institute for Earth Science and Disaster Prevention ( $\left.\mathrm{M}_{\mathrm{w}} \mathrm{NIED}\right)$ of Japan, as cited in ISC on-line bulletins.

Table 1 - Classification of moment magnitude data published in global earthquake catalogs.

\begin{tabular}{|c|c|c|c|c|}
\hline $\begin{array}{c}\text { Moment Magnitude } \\
\text { Group }\end{array}$ & $\begin{array}{c}\text { Moment Magnitude } \\
\text { Source }\end{array}$ & $\begin{array}{l}\text { Time Period } \\
\text { Coverage }\end{array}$ & $\begin{array}{l}\text { Magnitude } \\
\text { Range }\end{array}$ & $\begin{array}{c}\text { Maximum } \\
\text { Depth } \\
\text { (km) }\end{array}$ \\
\hline \multirow{3}{*}{$\mathrm{M}_{\mathrm{w}} \mathrm{H}$} & GCMT & \multirow{3}{*}{$1962-2010$} & \multirow{3}{*}{$4.6-8.2$} & \multirow{3}{*}{693} \\
\hline & SOPAR & & & \\
\hline & $\mathrm{CEC}$ & & & \\
\hline \multirow{3}{*}{$\mathrm{M}_{\mathrm{w}} \mathrm{N}$} & NEIC & \multirow{3}{*}{$1980-2010$} & \multirow{3}{*}{$4.1-8.2$} & \multirow{3}{*}{692} \\
\hline & PDE & & & \\
\hline & GS & & & \\
\hline $\mathrm{M}_{\mathrm{w}}$ NIED & NIED & $1997-2009$ & $3.2-7.5$ & 576 \\
\hline
\end{tabular}

Corresponding $\mathrm{M}_{\mathrm{w}}$ NIED moment magnitude values reach down to 3.2-3.3. On the other hand, $\mathrm{M}_{\mathrm{w}} \mathrm{H}$ and $\mathrm{M}_{\mathrm{w}} \mathrm{N}$ magnitudes exhibit their known global minima around 4.6 and 4.1 respectively. These variations in moment magnitude minima are due to different methodologies applied and the variety of the seismic waveforms' frequency content utilized through seismic moment measurements.

Thus, CMT methodology (Dziewonski et al., 1981) relies on long period seismic waves (T>45s) while moment tensors calculated by the USGS research group are based on body waveform analysis (T>15s) (Sipkin, 1982). On the other hand NIED's moment tensor inversion method (Fukuyama et al., 1999) is based on corrected ground displacements, filtered and resampled every $1 \mathrm{~Hz}$ (Kubo et. al., 2002), by using waveforms of maximum three broadband stations (FREESIA seismic network).

Direct comparison between moment magnitudes of $M_{w} H-M_{w} N$ subsets for earthquakes of $h \geq 60 \mathrm{~km}$ revealed their equivalence, confirming previous observations based on global shallow data (Scordilis, 2006). $M_{w}$ NIED is also considered to be identical to $M_{w} H$ and $M_{w} N$, respectively, for a wide range of magnitudes, even though some discrepancies may be noticed; as shown in Figure 1 the $\mathrm{M}_{\mathrm{w}} \mathrm{H}$ (open circles) and $\mathrm{M}_{\mathrm{w}} \mathrm{N}$ (light gray circles) exhibit lower saturation level around magnitude 5.0 as resulting from 289 and 101 values' pairs with $\mathrm{M}_{\mathrm{w}} \mathrm{NIED}$, respectively.

Focusing on $\mathrm{M}_{\mathrm{w}} \mathrm{H}$ data and by fitting a $4^{\text {th }}$ degree polynomial equation (solid line), the saturation trend seems to insist, whereas moving upwards to this level, linear fitting across the bisector (dashed line) indicates equivalence of the examined subsets. This is also consistent with the systematic change in tendency that has been observed for moment values around at $2 \times 10^{17} \mathrm{Nm}$ (Kubo et. al., 2002), attributed to different methodologies implemented by NIED and GCMT for seismic moment estimation.

XLVII, No $3-1318$ 


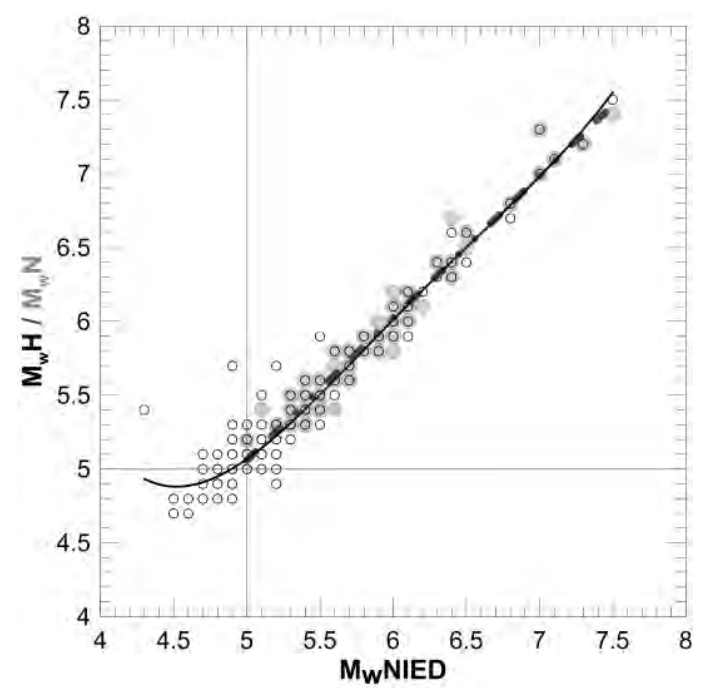

Figure 1 - Comparison between three distinguished categories of $M_{w}$, used in the present study. Dashed and solid lines represent linear and $4^{\text {th }}$ degree polynomial fitting, respectively.

It should be also noted that the significantly low minima of $\mathrm{M}_{\mathrm{w}}$ NIED's and the apparent lack of respective observations for $\mathrm{M}_{\mathrm{w}}$ NIED- $\mathrm{M}_{\mathrm{w}} \mathrm{N}$ is due to facts such as:

- NIED's moment tensor determination is supported by the national dense coverage of Japan's broadband seismic network FNET, and

- Relevant high value of minimum $\mathrm{M}_{\mathrm{w}}$ value according to the seismic moment calculations made by GCMT and NEIC research teams. Thus, only a small number of common events with relatively low moment magnitude data derived from both NIED and NEIC-USGS databases is available and consistently moment magnitude comparison is possible only for intermediate magnitude events $\left(\mathrm{M}_{\mathrm{w}}>5.0\right)$ located in the broader East Asia region.

Therefore, in order to obtain calibration relations of various scales with $\mathrm{M}_{\mathrm{w}}$ for a wide range of magnitude values, all the available moment magnitudes of NIED were adopted while only $\mathrm{M}_{\mathrm{w}}$ of moderate and strong events reported by GCMT and NEIC were included.

To achieve higher accuracy in focal depth estimation for intermediate and deep-focus earthquakes, valuable information is offered by reflected on Earth's surface $\mathrm{pP}$ waves, recorded on distant long period seismograms and published in ISC bulletins. This approach can be applied for $\Delta \mathrm{t}$ in arrival times of pP and P ray-paths, since they are strongly depended on focal depths. Once reliable $\mathrm{P}$ and $\mathrm{pP}$ observations are available, accurate focal depths are obtained by using appropriate (pP-P) travel time curves or tables. This information was embedded in the catalog replacing focal depth values proposed by other sources.

\section{Magnitude Conversion Relations}

Following recent published results (Utsu, 2002, Scordilis, 2006) based on shallow global datasets, body wave $\left(\mathrm{m}_{\mathrm{b}}\right)$ magnitudes, reported by ISC and NEIC, proved as well to be equivalent regarding intermediate-deep seismicity, composing a unified scale named $\mathrm{m}_{b} \mathrm{IN}$. Likewise, surface wave $\left(\mathrm{M}_{\mathrm{s}}\right)$ magnitudes originated from above centers, both determined by applying the Prague formula (Vanek et. al., 1962), also turned to be equivalent in this study forming unified scale, $\mathrm{M}_{\mathrm{s}} \mathrm{IN}$.

It is of interest to note that although $\mathrm{M}_{\mathrm{s}}$ is not suitable for earthquakes of focal depths greater than $\sim 50 \mathrm{~km}$ a considerable number of $\mathrm{M}_{\mathrm{s}}$ concerning deeper earthquakes is reported by sources used in the present study, and implied in a number of seismicity studies (Ambraseys \& Free, 1997, Gardini et. al., 1997 and others). 
Body wave magnitude $\left(\mathrm{m}_{\mathrm{B}}\right)$, estimated from long period records (Gutenberg, 1945c) is a scale of particular importance as concerning intermediate-deep seismicity (Frohlich, 2006), also utilized during this work.

\subsection{Body Wave Magnitude Scale $\left(\mathrm{m}_{\mathrm{b}} / \mathrm{m}_{\mathrm{B}}\right)$}

Body wave magnitude scales, $\mathrm{m}_{\mathrm{b}}$ and $\mathrm{m}_{\mathrm{B}}$, derived from short and long period recordings respectively, comprise the vast majority of magnitudes participating in our dataset and they were calibrated against $\mathrm{M}_{\mathrm{w}}$. This wide use of $\mathrm{m}_{\mathrm{b}}$, is due to its nature since this particular scale suits to the determination of deep events' magnitude (Frohlich, 2006), as well as to the easy determination procedures.
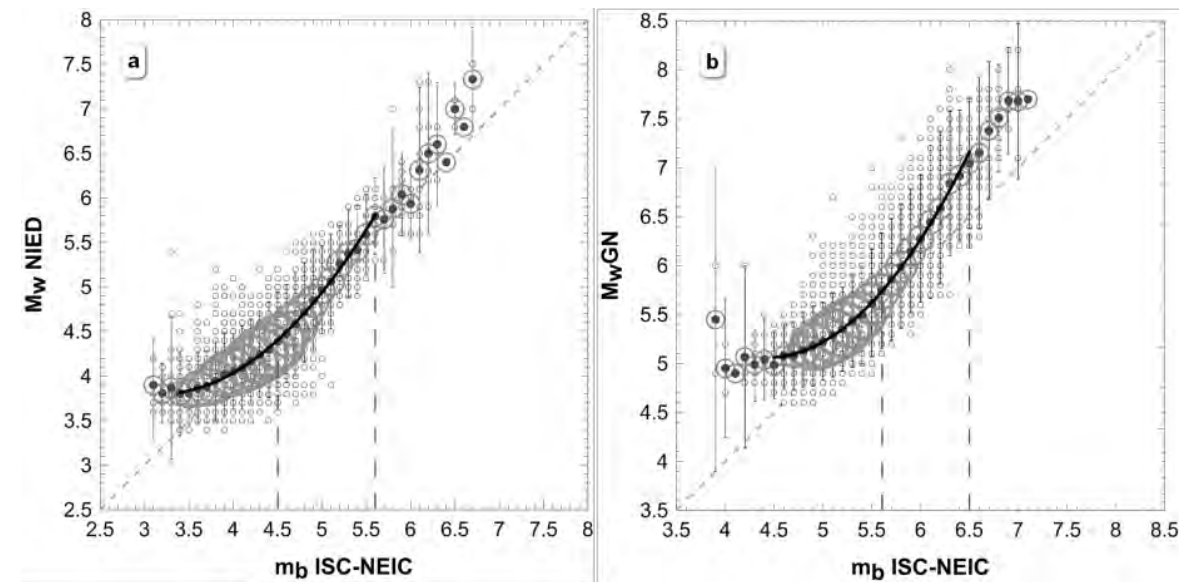

Figure 2 - Initial correlation plots between: a) $M_{w} N I E D$ and $m_{b} I N$ (left), and b) $M_{w} G N$ and $\mathrm{m}_{b} \mathrm{IN}$, (right) by applying 2nd degree polynomial fit (bisector is plotted as dashed line). Verti cal dashed lines delimit the almost linear part of the fit. Solid circles represent the mean $M_{w}$ NIED and MwGN values corresponding to each $m_{b} I N$ value while error-bars are for \pm 2 SD. Bubbles' size is related to the number of points used.

Direct comparison of $\mathrm{m}_{\mathrm{b}} \mathrm{IN}$ with $\mathrm{M}_{\mathrm{w}}$ NIED (Figure 2a) and moment magnitudes from GCMT and NEIC $\left(M_{w} G N\right)$ (Figure $2 b$ ), showed that a saturation-like behavior of $M_{w}$ is revealed for $m_{b} I N<5.6$ summarizing both cases. Therefore, in order to have a reliable and representative set of data only $\sim 6400$ pairs of $\mathrm{m}_{\mathrm{b}} \mathrm{IN}$ and $\mathrm{M}_{\mathrm{w}} \mathrm{GN}$ values with $\mathrm{M}_{\mathrm{w}} \mathrm{GN} \geq 5.6$ were integrated along with all the available pairs $\sim 5150$, of $\mathrm{m}_{\mathrm{b}} \mathrm{IN}$ and $\mathrm{M}_{\mathrm{w}} \mathrm{NIED}$, despite their magnitude range.

The respective graph given in Figure 3, exhibits a clear linear relation between moment magnitude and $m_{b} I N$ described in Table 1 . This relation, produced by applying standard linear regression (SR), showed slight difference compared to corresponding general orthogonal regression (GOR) equation (proposed by Fuller, 1987 and Castellaro et. al., 2006). It holds for $4.5 \leq \mathrm{m}_{\mathrm{b}} \mathrm{IN} \leq 7.0$, in agreement with Sipkin (2003), where saturation at lower $\mathrm{m}_{\mathrm{b}} \mathrm{IN}$ values (around 5.5) is attributed to the non-completeness of GCMT data. From the above it is obvious that for intermediate and deepfocus earthquakes the $m_{b}$ scale behaves completely different than for shallow ones (Kuge, 1992, Slipkin, 2003), not showing saturation for large $(M>6.0)$ events.

Subsequently, by applying this type of composite regression analysis, body wave magnitudes from other sources as MOS, BJI, IDC and DJA are calibrated (Figure 4). A case of special interest, since noticeable variation in the defined equations for intermediate and deep-focus earthquakes has been observed, is $\mathrm{m}_{\mathrm{b}}$ IDC. Linear regression fit for intermediate-depth events of IDC $(60 \mathrm{~km} \leq \mathrm{h} \leq 300 \mathrm{~km})$ was based on considerable more data, compared to that of deep seismicity $(\mathrm{h}>300 \mathrm{~km})$, resulting in more robust converting relation. Nevertheless, goodness of fit for $\mathrm{m}_{\mathrm{b}}$ IDC calibration of deep-focus events is acceptable for lower-upper cutoffs of 4.2 and 7.0, respectively. 


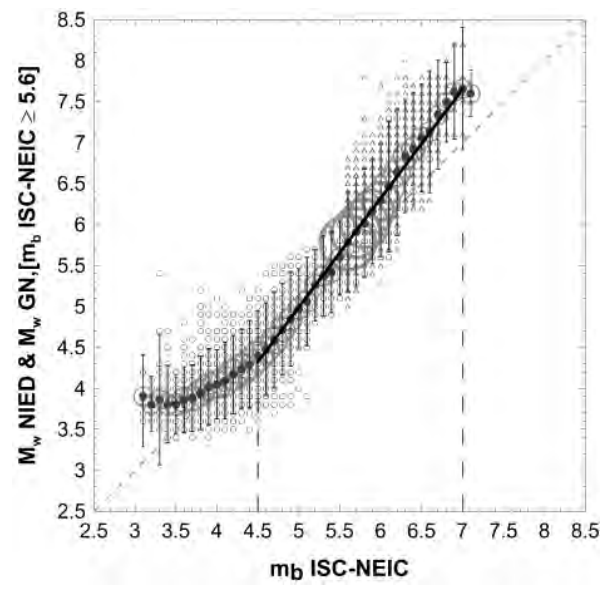

Figure 3 - Composite plot of $M_{w}$ NIED-M $M_{w} G N$ against $m_{b} I N$ by applying linear regression (SR). Open circles and triangles correspond to $M_{w} N I E D / m_{b} I N$ and $M_{w} G N / m_{b} I N$ pairs, respe ctively. Solid circles represent the mean MwNIED and MwGN values corresponding to each $m_{b} I N$ value while error-bars are for \pm 2 SD. Bubbles' size is related to the number of points $u$ sed. The same symbols hold for Figures 4, 5 and 6.
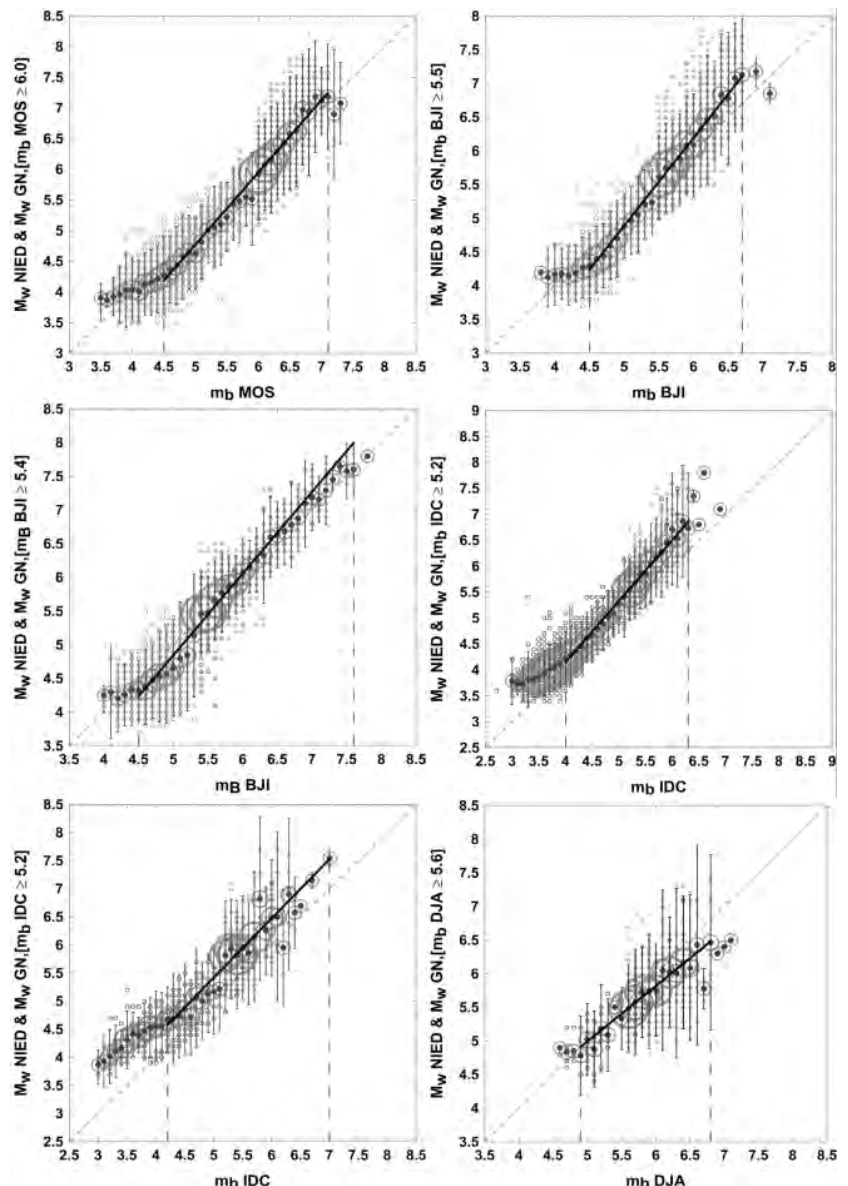

Figure 4 - From left to right, up to down raw: Composite plot of $M_{w}$ NIED-M ${ }_{w} G N$ against

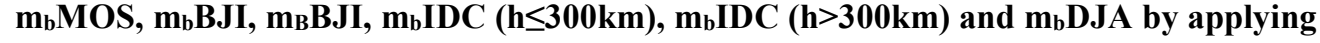
standard linear regression (SR). The symbols are as in figure 3. 


\subsection{Calibration of Surface Wave Magnitude $\left(M_{s}\right)$}

By comparing surface wave magnitudes $\mathrm{M}_{\mathrm{s}}$ reported from ISC/NEIC with moment magnitudes, a robust linear correlation with significant low standard errors for the upper part of the composite regression is obtained (Figure 5). Therefore, as the 1150 events participated in $\mathrm{M}_{\mathrm{S}} \mathrm{IN}$ 's regression analysis belong to depth range of $40-100 \mathrm{~km}$, adjusted linear equation takes effect strictly for intermediate-depth earthquakes.

Besides, a few more $M_{s}$ scales of great importance exhibiting linear behavior along with $M_{w}$ were also calibrated (Figure 5). Regression analysis of $\mathrm{M}_{\mathrm{S}} \mathrm{IDC}$ and $\mathrm{M}_{\mathrm{S}} \mathrm{BJI}$ shows relative results to ISC/NEIC data and in the second case least squares' fit extends up to a value of 7.2 demonstrating also similarities to the respective $\mathrm{M}_{\mathrm{s}} \mathrm{IN}$ equation. By analyzing less, but sufficiently enough, data ( 730 events), the $\mathrm{M}_{\mathrm{S}} \mathrm{MOS}$ vs $\mathrm{M}_{\mathrm{W}}$ regression yields a linear equation for an impressively wide range of 4.2 to 7.9. In that case and in order to achieve lower fit error we preferred to utilize single intermediate depth information, by excluding deep-focus events reported by $M_{s} M O S(h \geq 300 \mathrm{~km})$.
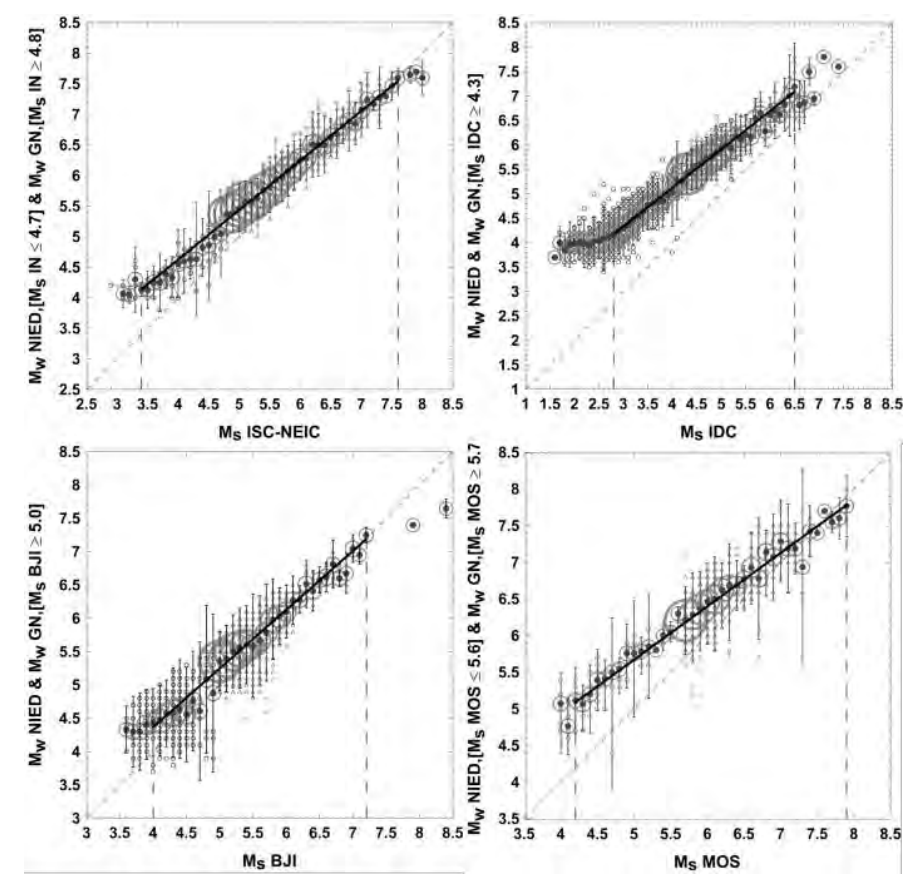

Figure 5 - From left to right, up to down raw: Composite plot of $M_{w} N I E D-M_{w} G N$ against $M_{s} I N, M_{s} I D C, M_{s} B J I$ and $M_{s} M O S(h \leq 300 \mathrm{~km})$ by applying standard linear regression (SR). The symbols are as in figure 3 .

\subsection{Calibration of Japan Meteorological Agency Magnitude Scale ( $\left.\mathbf{M}_{\mathrm{JMA}}\right)$}

Least squares correlation of moment magnitude with $\mathrm{M}_{\mathrm{JMA}}$, in the framework of a unified regression analysis, is depicted in Figure 6. As $\mathrm{M}_{\mathrm{JMA}}$ is a local magnitude calculated for the broader region of Japan, its comparison with $\mathrm{M}_{\mathrm{w}}$ exhibits a very tight linear adjustment for the lower part of the fit. A relative small number of events $(\sim 300)$ with $\mathrm{M}_{\mathrm{JMA}} \geq 6.1$ and reported $\mathrm{M}_{\mathrm{w}} \mathrm{GN}$ values give the option of extending the linear fit up to 7.6. 


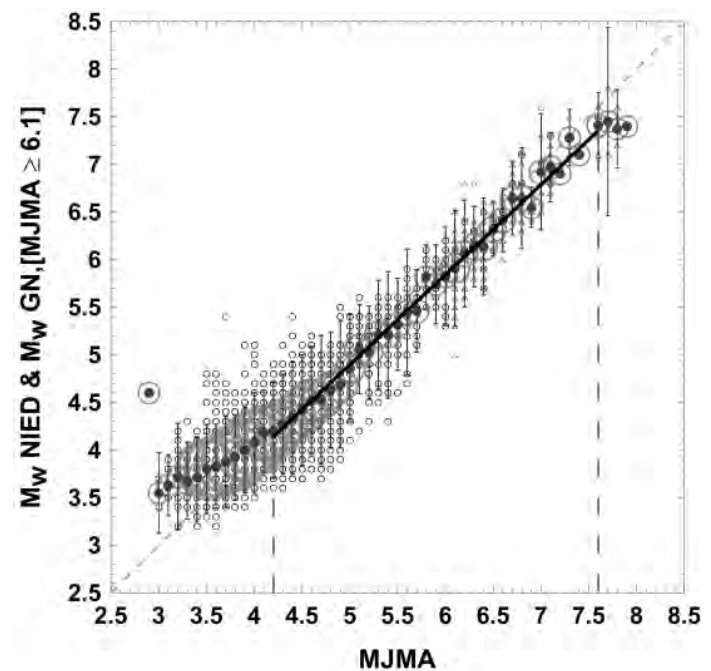

Figure 6 - Composite plot of $M_{w}$ NIED-M $M_{w} G N$ against $M_{J M A}$ by applying linear regression. The symbols are as in figure 3 .

Table 2 - Linear regression coefficients derived after correlating $M_{w}$ with 11 available magnitude scales for intermediate and deep-focus earthquakes globally

\begin{tabular}{|c|c|c|c|c|c|c|c|c|}
\hline & $\begin{array}{c}\text { Calibrated Magnitude } \\
\text { Scales }\end{array}$ & b & a & $\sigma$ & $\mathbf{R}^{2}$ & $\mathrm{n}$ & $\mathbf{M}_{\min }$ & $\mathbf{M}_{\max }$ \\
\hline \multirow{7}{*}{ 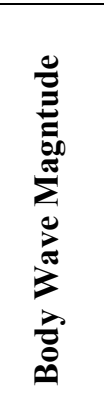 } & $\mathrm{m}_{b} \mathrm{IN}$ & 1.331 & -1.669 & 0.33 & 0.82 & 8216 & 4.5 & 7.0 \\
\hline & $\mathrm{m}_{\mathrm{b}} \mathrm{MOS}$ & 1.178 & -1.110 & 0.38 & 0.83 & 3039 & 4.5 & 7.1 \\
\hline & $\mathrm{m}_{b} \mathrm{BJI}$ & 1.303 & -1.625 & 0.33 & 0.83 & 3520 & 4.5 & 6.7 \\
\hline & $\mathrm{m}_{\mathrm{B}} \mathrm{BJI}$ & 1.213 & -1.224 & 0.31 & 0.84 & 3078 & 4.5 & 7.6 \\
\hline & \multirow{2}{*}{$\begin{array}{cl} & \mathrm{h} \leq 300 \mathrm{~km} \\
\mathrm{~m}_{\mathrm{b}} \mathrm{IDC} & \mathrm{h}>300 \mathrm{~km}\end{array}$} & 1.177 & -0.557 & 0.32 & 0.85 & 1749 & 4.0 & 6.3 \\
\hline & & 1.052 & 0.158 & 0.49 & 0.61 & 430 & 4.2 & 7.0 \\
\hline & $\mathrm{m}_{\mathrm{b}} \mathrm{DJA}$ & 0.826 & 0.865 & 0.42 & 0.37 & 556 & 4.9 & 6.8 \\
\hline \multirow{4}{*}{ 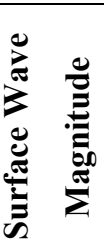 } & $\mathrm{M}_{\mathrm{S}} \mathrm{IN}$ & 0.810 & 1.384 & 0.20 & 0.89 & 1150 & 3.4 & 7.6 \\
\hline & $\mathrm{M}_{\mathrm{s}} \mathrm{IDC}$ & 0.786 & 1.977 & 0.26 & 0.86 & 1810 & 2.8 & 6.5 \\
\hline & $\mathrm{M}_{\mathrm{s}} \mathrm{BJI}$ & 0.881 & 0.844 & 0.30 & 0.80 & 1206 & 4.0 & 7.2 \\
\hline & $\mathrm{M}_{\mathrm{s}} \mathrm{MOS}$ & 0.728 & 2.030 & 0.27 & 0.75 & 731 & 4.2 & 7.9 \\
\hline Other & $\mathrm{M}_{\mathrm{JMA}}$ & 0.945 & 0.170 & 0.28 & 0.89 & 1635 & 4.2 & 7.6 \\
\hline
\end{tabular}

Additionally, two more observations concerning regression analysis of $\mathrm{M}_{\mathrm{IMA}}$ could be done:

- homogeneity of error distribution between lower and upper section of the fit, with estimated errors remaining almost stable for both parts, and

- particularly high $\mathrm{M}_{\mathrm{JMA}}$ value (6.1) around which integration of $\mathrm{M}_{\mathrm{w}}$ NIED and $\mathrm{M}_{\mathrm{w}} \mathrm{GN}$ values is obtained. 


\section{Conclusions}

The purpose of the present work was to define reliable empirical relations converting magnitudes expressed in several magnitude scales into moment magnitudes, valid for intermediate and deepfocus earthquakes globally. Such twelve new converting relations were derived for $\mathrm{m}_{\mathrm{b}}, \mathrm{m}_{\mathrm{B}}$ and $\mathrm{M}_{\mathrm{s}}$ magnitudes reported by ISC, NEIC, MOS, BJI, IDC, DJA, MOS and JMA (Table 2). A remarkable observation is that $m_{b}$ scale doesn't appear to saturate for large magnitudes, an effect that is clearly observed for shallow earthquakes' body wave magnitudes around 6.2. The linear relation defined between $m_{b}$ and $M_{w}$ seems to extend up to the value of 7.0. The lack of such a saturation is also indicated by the distinct examination of $\mathrm{m}_{\mathrm{b}}$ determined for intermediate and deep-focus earthquakes separately, confirming the fact in both of these cases.

Even though $\mathrm{M}_{\mathrm{s}}$ is not recommended for intermediate and deep-focus earthquakes, surface wave magnitudes are reported for non-shallow earthquakes by international institutes. Correlation of $\mathrm{M}_{\mathrm{s}}$, reported by several centers, with $\mathrm{M}_{\mathrm{w}}$ showed clear and robust linear dependence of these scales for a wide range of magnitude values. Strong linear connection was also revealed after comparing $\mathrm{M}_{\mathrm{JMA}}$ with $\mathrm{M}_{\mathrm{w}}$.

A remarkable observation made in this study is the different behavior of $\mathrm{M}_{\mathrm{w}}$ reported by GCMT and/or NEIC $\left(M_{w} G N\right)$ and the $M_{w}$ of NIED. Thus, the $M_{w} G N$ for values bellow $~ 5.0$ seems to be independent of the real magnitude while similar behavior is also observed for $\mathrm{M}_{\mathrm{w}}$ NIED but for smaller magnitude values.

The relations proposed in the present study can be used to produce homogeneous, in respect to magnitude, earthquake catalogs of intermediate and deep-focus earthquakes globally.

\section{Acknowledgments}

This research has been co-financed by the European Union (European Social Fund - ESF) and Greek national funds through the Operational Program "Education and Lifelong Learning" of the National Strategic Reference Framework (NSRF) - Research Funding Program: THALES. Investing in knowledge society through the European Social Fund. Project SEISMO FEAR HELLARC. Geophysics Department Contribution Number 806/2013.

\section{References}

Abe K. 1981. Magnitudes of large shallow earthquakes from 1904 to 1980, Phys. Earth Planet. Int. 27, 72-92.

Abe K. and Kanamori H. 1979. Temporal variation of the activity of intermediate and deep focus earthquakes, Journal of Geophysical Research, 84, 87, 3589-3595.

Ambraseys N. and Free M. 1997. Surface-wave magnitude calculation for European region earthquakes., Journ. Earthq. Eng., 1, 1, 1-22.

Astiz L., Lay T. and Kanamori H. 1988. Large intermediate-depth earthquakes and the subduction process, Phys. Earth Planet. Int., 53, 80-166.

Bath M. and Duda S. J. 1979. Some aspects of global seismicity: Report No. 1-79, Seismological Institute, Uppsala, Sweden, 1- 41.

Castellaro S., Mulargia F. and Kagan. Y. Y. 2006. Regression problems for magnitudes, Geophys. J. Int., 165, 913-930.

Dziewonski A. M. and Gilbert F. 1974. Temporal variation of the seismic moment tensor and the evidence of precursive compression for two deep earthquakes, Nature, 247, 185-188.

Dziewonski A. M., Chou T. A. and Woodhouse J. H. 1981. Determination of earthquake source parameters from waveform data for studies of global and regional seismicity, J. Geophys. Res., 86(2), 825-852. 
Engdahl E.R. and Villaseñor A. 2002. Global Seismicity: 1900-1999, In W.H.K. Lee, H. Kanamori, P.C. Jennings and C. Kisslinger (editors), International Handbook of Earthquake and Engineering Seismology, Part A, Chapter 41, Academic Press, 665-690.

Frohlich C. 2006. Deep Earthquakes, Cambridge University Press, Cambridge, England.

Fukuyama E., Ishida M., Horiuchi S., Inoue H., Hori S., Sekiguchi S., Kawai H. and Murakami H. 1999. NIED seismic moment tensor catalogue January - December, 1998. TechnicalNote Natl. Res. Inst. Earth Sci. Disaster Prev., 193, 1 - 35.

Fuller W. A. 1987. Measurement Error Models, Wiley, New York.

GCMT 2012. Global Centroid Moment Tensor (GCMT) project at Lamont-Doherty Earth Observatory (LDEO) of Columbia University, http://www.globalcmt.org/CMTsearch.html.

Giardini D. 1988. Frequency distribution and quantification of deep earthquakes, J. Geophys. Res. 93, 2095- 2105.

Gardini D., Donato M. di. and Boschi E. 1997. Calibration of magnitude scales for earthquakes of the Mediterranean, Journal of Seismology, 1, 161-180.

Gutenberg B. 1945. Magnitude determination for deep-focus earthquakes, Bull. Seism. Soc. Am. $35,117-130$.

International Seismological Centre (ISC) 2012. On-line Bulletin, http://www.isc.ac.uk, Internatl. Seis. Cent., Thatcham, United Kingdom, http://www.isc.ac.uk/iscbulletin/search/bulletin.

Karnik V. 1996. Seismicity of Europe and the Mediterranean, In: Klima, K. (ed.), Academy of Sciences of the Czech Republic, Geophysical Institute, 28 pp. plus earthquake catalogue.

Kubo A., Fukuyama E., Kawai H. and Nonomura K. 2002. NIED seismic moment tensor catalogue for regional earthquake around Japan: Quality test and application, Tectonophys., 356, 23-48 pp.

Kuge K. 1992. Systematic difference in the ISC body-wave magnitude - seismic moment relationship between intermediate and deep earthquakes, Bull. Seismo. Soc. Amer., 82, 819-835.

National Earthquake Information Center, (NEIC) 2011. Earthquake Hazards Program, URL: http://neic.usgs.gov/neis/epic/index.html.

Okal E.A. and Kirby S.H. 1995. Frequency-moment distribution of deep earthquakes; implications for the seismogenic zone at the bottom of slabs, Phys. Earth Planet. Interiors, 92, 169- 187.

Scordilis E.M. 2006. Empirical global relations converting Ms and mb to moment magnitude, Journal of Seismology, 10, 225-236.

Sipkin S.A. 1982. Estimation of earthquake source parameters by the inversion of waveform data: synthetic seismograms, Physics of the Earth and Planetary interiors, v. 30, no. 2-3, 242259.

Sipkin S.A. 2003. A correction to body-wave magnitude mb based on moment magnitude Mw, Seis. Res. Lett., 74, 739-742.

SOPAR 2012. Source Parameter Search (SOPAR) - Moment Tensor and Broadband Source Parameter Search, USGS-NEIC, http://earthquake.usgs.gov/earthquakes/eqarchives/sopar.

Utsu T. 2002. Relationships between magnitude scales, International Handbook of Earthquake and Engineering Seismology, 81, 733-746.

Wadati K. 1928. Shallow and Deep Earthquakes, Geophysical Magazine, 1, 162-202.

Wadati K. 1929. Shallow and Deep Earthquakes, Geophysical Magazine, 2, 1- 36. 